\title{
Perikelen rond de vaststelling en publicatie van de jaarrekening en aansprakelijkheid in het kader daarvan. Een reactie
}

\author{
Prof. mr. C.A. Schwarz en Mr. dr. R.A. Wolf
}

In deze bijdrage wordt bepleit dat de overeenkomstig artikel 2:210 lid 5 BW vereenvoudigd vastgestelde jaarrekening binnen acht dagen na haar vaststelling gedeponeerd moet worden om te voorkomen dat het onweerlegbare vermoeden van onbehoorlijk bestuur van artikel 2:248 lid 2 BW zal gelden en de bestuurder daardoor in een lastige(re) procespositie komt te verkeren. Beter zou zijn dat artikel 2:21o lid 5 BW geschrapt of gewijzigd wordt of dat statutair van deze bepaling wordt afgeweken.

\section{Inleiding}

Van Hooff geeft in het Maandblad voor Ondernemingsrecht ${ }^{1}$ enkele interessante bespiegelingen over de publicatieplicht en bestuurdersaansprakelijkheid. Graag geven wij een reactie op de stelling van Van Hooff dat schending van de publicatieplicht van artikel 2:210 lid 5 jo. artikel 2:394 lid 1 van het Burgerlijk Wetboek (BW) niet leidt tot bestuurdersaansprakelijkheid in de zin van artikel 2:248 lid 1 of 2 BW.

Artikel 2:210 lid 5 BW is een ongelukkige bepaling, die vele pennen in beweging heeft gebracht. ${ }^{2}$ De wetgever heeft twee keer een kans gemist om de onduidelijkheid of de mogelijk ongewenste gevolgen van deze bepaling weg te nemen. De eerste kans was de Verzamelwet Veiligheid en Justitie $2013 \cdot{ }^{3}$ De tweede kans was de Uitvoeringswet richtlijn jaarrekening. 4

\section{De publicatietermijn van de jaarrekening}

De jaarrekening doorloopt op hoofdlijnen de volgende stappen: het opmaken door het bestuur, ${ }^{5}$ het vaststellen door de algemene vergadering ${ }^{6}$ en tot slot de publicatie door de rechtspersoon. ${ }^{7}$ Bij de laatste stap van de publicatie van de jaarrekening kunnen twee situaties worden onderscheiden.

In de eerste situatie is sprake van een vastgestelde jaarrekening. In dat geval bepaalt de wet dat de jaarrekening binnen acht dagen na vaststelling moet worden gepubliceerd (art. 2:394 lid 1 BW). De conclusie kan niet anders zijn dan dat ook in het geval van een vereenvoudigde vaststelling op grond van het bepaalde in artikel 2:210 lid 5 BW die publicatietermijn geldt. Van Hooff is het overigens met deze conclusie eens. $^{8}$

In de tweede situatie is de jaarrekening wel opgemaakt, maar nog niet vastgesteld. Artikel 2:394 lid 2 BW bepaalt dat de opgestelde jaarrekening onverwijld moet worden gepubliceerd wanneer deze niet is 
17-2-2016 Perikelen rond de vaststelling en publicatie van de jaarrekening en aansprakelijkheid in het kader daarvan. Een reactie $\cdot$ Maandblad voor Ondernemingsre...

vastgesteld binnen twee maanden na het verstrijken van de voor het opmaken voorgeschreven termijn. Deze (laatste) termijn bedraagt vijf maanden na de balansdatum (art. 2:210 lid 1 BW). Deze termijn kan worden verlengd met ten hoogste zes maanden bij besluit van de algemene vergadering op grond van bijzondere omstandigheden. Dat de Hoge Raad in het arrest Brens q.q./Sarper ${ }^{9}$ niet zwaar tilt aan de vereisten voor het verlengen van de termijn bij besluit van de algemene vergadering moge zo zijn, een en ander neemt niet weg dat het opstellen van de jaarrekening uiterlijk binnen elf maanden na balansdatum moet zijn afgerond. Artikel 2:394 lid 3 BW bepaalt dat de jaarrekening, wat ook de geldende termijn voor opstelling moge zijn, in ieder geval uiterlijk binnen dertien maanden na het einde van het boekjaar gepubliceerd moet worden. Wordt de jaarrekening binnen twee maanden na het verstrijken van de opmaaktermijn, zoals bedoeld in artikel 2:210 lid $1 \mathrm{BW}$, toch vastgesteld, dan geldt dat de jaarrekening binnen acht dagen na de vaststelling gepubliceerd moet worden met als uiterste termijn de dertienmaandentermijn. ${ }^{10}$ De Uitvoeringswet richtlijn jaarrekening verkort (1) de dertienmaandentermijn van artikel. 2:394 lid 3 BW tot twaalf maanden en (2) de verlengingstermijn van zes maanden van artikel 2:210 lid $1 \mathrm{BW}$ tot vijf maanden voor boekjaren vanaf 2016. In het onderstaande zal van de thans nog geldende termijnen voor het boekjaar 2015 worden uitgegaan.

Van Hooff concludeert dat in beide situaties alleen de termijn van dertien maanden relevant is voor het antwoord op de vraag wat te laat publiceren is. Hij schrijft: 'Voor de toepassing van artikel 2:248 lid 2 BW is de achtdagentermijn echter niet relevant. ${ }^{11}$ Als dat zo is, dan is artikel 2:394 lid 1 BW een dode letter. Anders gezegd, het onderscheid tussen een vastgestelde en niet-vastgestelde jaarrekening is kennelijk volgens Van Hooff - voor wat betreft de termijn waarbinnen deze jaarrekeningen gepubliceerd moeten worden, niet (meer) relevant. Sluitende argumentatie voor dit standpunt treffen wij echter niet aan, laat staan dat aan een cliënt enige zekerheid kan worden gegeven met betrekking tot de vraag of deze visie in rechte overeind zal blijven. Wij geven Van Hooff direct toe dat de regeling van artikel 2:210 lid 5 BW ondoordacht is. Een betrokken jurist zal in een voorkomend geval waarschijnlijk geneigd zijn de ongerijmdheid van de regeling weg te redeneren door het ontwikkelen van de door Van Hooff voorgestane opvatting. Wij menen echter dat het essentieel is dat zekerheid moet kunnen worden verstrekt over het feit dat die opvatting ook in een aansprakelijkheidsprocedure overeind zal blijven. Die zekerheid is er niet. Sterker nog, de minister acht het verschil tussen een vastgestelde en niet-vastgestelde jaarrekening, en de publicatietermijnen die in dat kader gelden, wel degelijk relevant. In de memorie van toelichting bij de Uitvoeringswet richtlijn jaarrekening is het volgende te lezen: ${ }^{12}$

'In Nederland geldt thans op basis van het derde lid van artikel 394 een uiterste publicatietermijn van dertien maanden na afloop van het boekjaar. (...) De nieuwe voorgeschreven publicatietermijn heeft tot gevolg dat de uiterste publicatietermijn in het derde lid van artikel 394 van dertien maanden wordt verkort tot twaalf maanden. Het tweede lid van artikel 394 schrijft voor dat de opgemaakte jaarrekening openbaar moet worden gemaakt indien de jaarrekening niet binnen 
twee maanden na de termijn voor het opmaken van de jaarrekening is vastgesteld. De termijn voor het opmaken van de jaarrekening is voor NV's en BV's vijf maanden na afloop van het boekjaar. Deze termijn kan door de algemene vergadering wegens bijzondere omstandigheden worden verlengd met zes maanden (artikel 2:101 en 210 $B W$ ). Hiermee komt de uiterste termijn voor het opmaken van de jaarrekening op elf maanden. (...) Op basis van het huidige recht kan men daarmee uitkomen op een uiterste publicatietermijn van de (opgemaakte) jaarrekening van dertien maanden: vijf of zes maanden voor het opmaken van de jaarrekening plus zes of vijf maanden uitstel van het opmaken, plus twee maanden om de jaarrekening vast te stellen, maakt in totaal dertien maanden. Omdat de uiterste publicatietermijn niet meer dan twaalf maanden mag bedragen, wordt voorgesteld de verlengingstermijn van zes maanden voor NV's en BV's (...) met een maand te verkorten.'

De publicatietermijn van dertien maanden wordt door de minister dus uitsluitend in het kader van artikel 2:394 lid 2 en 3 BW geplaatst. Is de jaarrekening vastgesteld, dan geldt artikel 2:394 lid 1 BW onverkort. ${ }^{13}$ Dat volgt ook uit de memorie van toelichting bij de Verzamelwet Veiligheid en Justitie 2013:14

$$
\begin{aligned}
& \text { 'De datum van vaststelling heeft ook gevolgen voor de deponering bij het } \\
& \text { handelsregister, die immers binnen acht dagen na vaststelling van de jaarrekening } \\
& \text { moet plaatsvinden (artikel } 394 \text { lid 1).' }
\end{aligned}
$$

Aan deze regel is ook vastgehouden in de Wet elektronisch deponeren van bescheiden in het handelsregister. ${ }^{15}$ Op grond van deze wetswijziging kan de jaarrekening uitsluitend langs elektronische weg bij het handelsregister worden aangeleverd. Deponering wordt dus (nog) makkelijker. Op het moment van schrijven van deze bijdrage was de datum van inwerkingtreding van deze wetswijziging nog niet bekend. ${ }^{16}$ Na inwerkingtreding geldt een gewijzigde tekst van artikel 2:394 lid 1 BW.

\section{Tijdige publicatie en bestuurdersaansprakelijkheid ex artikel 2:248 BW}

Het tijdig publiceren van de jaarrekening na haar vaststelling is van belang bij de vaststelling van de externe bestuurdersaansprakelijkheid van artikel 2:248 BW. Het systeem in die bepaling is dat bij faillissement van de vennootschap bestuurders hoofdelijk aansprakelijk zijn als sprake is geweest van onbehoorlijke taakvervulling en als dit een belangrijke oorzaak is geweest van het faillissement (lid 1). Als het bestuur niet heeft voldaan aan zijn verplichting tot tijdige openbaarmaking van de jaarrekening ex artikel 2:394 BW, of niet voldaan heeft aan de boekhoudplicht ex artikel 2:10 BW, geldt op basis van artikel 2:248 lid 2 BW dat het bestuur zijn taak onbehoorlijk heeft vervuld. Tevens geldt het weerlegbare vermoeden van artikel 2:248 lid 2 BW. Dit vermoeden houdt in dat wanneer het bestuur niet heeft voldaan aan zijn verplichting van artikel 2:10 of 2:394 BW, wordt vermoed dat dit een belangrijke oorzaak van het faillissement van de vennootschap is. De curator bevindt zich in dat geval in een makkelijke positie. Hij 
17-2-2016 Perikelen rond de vaststelling en publicatie van de jaarrekening en aansprakelijkheid in het kader daarvan. Een reactie $\cdot$ Maandblad voor Ondernemingsre...

hoeft slechts te stellen dat de jaarstukken niet tijdig gepubliceerd zijn. De bestuurder is dan aansprakelijk, tenzij (1) sprake is van een onbelangrijk verzuim, (2) het faillissement het gevolg is van een andere oorzaak (en niet van de onbehoorlijke taakvervulling van het bestuur op basis van het niet voldoen aan de verplichting van art. 2:10 of 2:394 BW), (3) de onbehoorlijke taakvervulling van het bestuur op basis van het niet voldoen aan de verplichting van artikel 2:10 of 2:394 BW niet aan de bestuurder in kwestie is te wijten en (4) de aansprakelijkheid van de bestuurder voor het boedeltekort moet worden gematigd tot nihil.

Uit het Van Schilt/Jansen-arrest ${ }^{17}$ volgt dat artikel 2:248 lid 2 BW ziet op alle verplichtingen voortvloeiende uit artikel 2:394 BW. Daarmee verdraagt zich niet de stelling van Van Hooff dat schending van de artikel 2:394 BW-verplichting niet leidt tot de toepasselijkheid van artikel 2:248 lid 2 BW. ${ }^{18}$ Immers, vanwege deze schending staat vast dat het bestuur zijn taak onbehoorlijk heeft vervuld. In beginsel is daarmee de aansprakelijkheid van het bestuur een gegeven, waarbij de bewijslast ten aanzien van het causaal verband tussen het onbehoorlijk bestuur en het faillissement van de vennootschap wordt 'omgedraaid'. De enige manier om aan de aansprakelijkheid op basis van artikel 2:394 jo. artikel 2:248 lid 2 BW te ontkomen, is het weerleggen van het vermoeden dat de onbehoorlijke taakvervulling geen belangrijke oorzaak is van het faillissement van de vennootschap. Op de bestuurder(s) $\operatorname{lig}(\mathrm{t})(\mathrm{gen})$ daarvan de stelplicht en de bewijslast. ${ }^{19}$

Gelet op dit wettelijke systeem hebben wij er eerder op gewezen dat een bestuurder persoonlijk aansprakelijk kan zijn bij niet-tijdige deponering. Ter vermijding van dit risico doet het bestuur er, gelet op het voorgaande, goed aan de jaarrekening tijdig na haar vereenvoudigde vaststelling te deponeren en niet de termijn van dertien maanden af te wachten. ${ }^{20}$

In de literatuur wordt op grond van het Brens q.q./Sarper-arrest ${ }^{21}$ aangenomen dat een depot van de vastgestelde jaarrekening binnen de termijn van dertien maanden na einde boekjaar (art. 2:394 lid 3 BW) niet leidt tot boedelaansprakelijkheid ex artikel 2:248 lid 2 BW. ${ }^{22}$ Ook Van Hooff huldigt deze opvatting onder verwijzing naar literatuur en dit arrest. ${ }^{23}$ De Hoge Raad overwoog:

'Bij de beantwoording van de vraag of een niet tijdig voldoen aan de in art. 2:394 neergelegde publikatieverplichting al dan niet een onbelangrijk verzuim als vorenbedoeld oplevert, moet in aanmerking worden genomen dat de ingrijpende bepaling van art. 2:248 lid 2 eerste zin haar rechtvaardiging vindt in het belang dat crediteuren van de vennootschap hebben bij naleving van de daar vermelde voorschriften, en dat het voor die crediteuren niet van belang is of de termijn voor het opmaken van de jaarrekening op formeel juiste wijze is verlengd, aangezien zij in elk geval rekening dienen te houden met de mogelijkheid dat tot de door de wet toegestane verlenging is besloten. De regels betreffende de termijnen waarbinnen volgens art. 2:210 het bestuur zijn daar bedoelde voorbereidende taak moet verrichten en de wijze waarop de algemene vergadering aan het bestuur nog een 
verlenging kan toestaan, zijn van belang voor de taakverdeling binnen de vennootschap. Voor de crediteuren is in feite slechts van belang dat de jaarrekening niet later wordt gepubliceerd dan op het uiterste tijdstip dat in geval van verlenging van de termijn voor het opmaken geldt, dus uiterlijk dertien maanden na afloop van het boekjaar. Een redelijke uitleg van het bepaalde in art. 2:248 brengt daarom mee dat bij de beantwoording van voormelde vraag een overschrijding van de termïn voor openbaarmaking buiten beschouwing wordt gelaten voor zover die overschrijding het gevolg is van het ontbreken van een geldig besluit tot verlenging van de termijn geldende voor het opmaken van de jaarrekening.'(r.o. 3.3)

Naar onze mening heeft het Brens q.q./Sarper-arrest alleen betrekking op de situatie waarin geen verlengingsbesluit in de zin van artikel 2:210 lid $1 \mathrm{BW}$ is genomen. Over vaststelling rept de Hoge Raad niet. In het geval van een vereenvoudigde vaststelling in de zin van artikel 2:210 lid 5 BW gaat het niet om een verlengingsbesluit voor het opmaken van de jaarrekening. Artikel 2:210 lid 5 BW ziet op de wijze van vaststelling van de jaarrekening. Kort gezegd, bepaalt dat artikellid dat als alle aandeelhouders ook bestuurder van de vennootschap zijn, de ondertekening van de jaarrekening tevens als haar vaststelling geldt. Op grond van artikel 2:394 lid 1 BW moet de op die wijze vastgestelde jaarrekening vervolgens binnen acht dagen worden gepubliceerd. De Hoge Raad noemt in het Brens q.q./Sarper-arrest de dertienmaandentermijn slechts in het kader van het 'uiterste tijdstip' voor publicatie van de jaarrekening. Zoals gesteld, er kan echter al eerder een verplichting tot publicatie zijn ontstaan. ${ }^{24}$

Gelijk A-G Asser in zijn conclusie onder het arrest schreef, is het besluit tot verlenging van de termijn om de jaarrekening op te maken een besluit met interne werking. De algemene vergadering geeft het bestuur van de vennootschap een langere termijn voor het opmaken van de jaarrekening. Deze besluitvorming is voor derden, onder wie crediteuren, onzichtbaar. De Hoge Raad kende daarom aan het ontbreken van dit besluit, terecht, geen gewicht toe.

\section{De vereenvoudigde vaststelling van de jaarrekening: een extern besluit}

Bij een vereenvoudigde vaststelling van de jaarrekening is (ook) de vraag aan de orde of sprake is van een extern besluit. Zoals wij eerder opgemerkt hebben, is dat onduidelijk. ${ }^{25}$ Wij zouden vooralsnog tot uitgangspunt willen nemen dat de vereenvoudigde vaststelling van de jaarrekening in de zin van artikel 2:210 lid 5 BW externe werking heeft, althans beoogt te hebben. De minister beschouwt de publicatieverplichting als een 'zeer fundamentele verplichting van het bestuur' of 'een van de wezenlijke ten opzichte van derden die met de vennootschap te maken hebben meest belangrijke bestuurstaken'. ${ }^{26}$ Ook het citaat uit de memorie van toelichting van het eerdergenoemde voorstel van de Verzamelwet wijst op het feit dat de publicatieverplichting een van de belangrijkste bestuurstaken is. Ook wijst de minister in deze memorie van toelichting nogmaals op de datum van vaststelling en tijdige publicatie. ${ }^{27}$

Geparafraseerd zou kunnen worden opgemerkt dat de termijn van dertien maanden geldt als het moment 
17-2-2016 Perikelen rond de vaststelling en publicatie van de jaarrekening en aansprakelijkheid in het kader daarvan. Een reactie $\cdot$ Maandblad voor Ondernemingsre...

waarop belanghebbenden uiterlijk kennis moeten kunnen nemen van een al dan niet vastgestelde jaarrekening, en dat deze termijn in geval van een artikel 2:210 lid 5 BW-situatie een kortere termijn, namelijk een termijn van elf maanden en acht dagen, is. Immers, belanghebbenden weten dat in het geval van een 'één directeur-grootaandeelhouder'-situatie de jaarrekening uiterlijk binnen elf maanden en acht dagen moet zijn gepubliceerd.

\section{Conclusie}

De essentie van al het voorgaande is dat een bestuurder van een vennootschap moet vermijden ooit in een artikel 248 lid 2 BW-situatie terecht te komen. Als de jaarrekening niet binnen elf maanden en acht dagen na haar vereenvoudigde vaststelling gepubliceerd wordt, dan is de onbehoorlijke taakvervulling een feit. Processueel staat de bestuurder dan 1-0 achter. Hij moet het vervolgens hebben van het weerlegbare vermoeden van ontbreken van causaliteit. Meer in het bijzonder moet hij stellen en bewijzen dat deze onbehoorlijke taakvervulling geen belangrijke oorzaak van het faillissement van de vennootschap is. Een onbelangrijk verzuim wordt niet in aanmerking genomen. In het Verify-arrest ${ }^{28}$ heeft de Hoge Raad de regels daarover nog eens op een rij gezet:

'Van een onbelangrijk verzuim als bedoeld in de slotzin van art. 2:248 lid $2 B W$ is sprake indien het niet voldoen aan de verplichtingen als bedoeld in dat artikellid in de omstandigheden van het geval niet erop wijst dat het bestuur zijn taak onbehoorlijk heeft vervuld. Dit is met name het geval indien voor het verzuim een aanvaardbare verklaring bestaat. Indien het, zoals in dit geval, gaat om een overschrijding van de termijn van art. 2:394 lid 3 BW voor openbaarmaking van de jaarrekening, geldt dat het antwoord op de vraag of een overschrijding als een onbelangrijk verzuim kan gelden, afhangt van de omstandigheden van het geval, in het bijzonder van de redenen die tot de termijnoverschrijding hebben geleid, waarbij opmerking verdient dat hogere eisen moeten worden gesteld naarmate de termijnoverschrijding langer is en dat stelplicht en bewijslast op de aangesproken bestuurder rusten (HR 12 juli 2O13, ECLI:NL:HR:2013:BZ7189).'

En:

'(...) in geval van een relatief korte overschrijding van de termijn van art. 2:394 lid 3 $B W[z i j n]$ geen hoge eisen (...) te stellen aan de verklaring die daarvoor wordt gegeven (vgl. HR 11 juni 1993, ECLI:NL:HR:1993:ZCo994, NJ 1993/713 en HR 2 februari 1996, ECLI:NL:HR:1996:ZC1981, NJ 1996, 406).’

Bij een onbelangrijk verzuim speelt de dertienmaandentermijn dus wél een rol. Echter, in een faillissement is er meestal meer aan de hand dan alleen het niet-tijdig publiceren van de jaarrekening. 
17-2-2016 Perikelen rond de vaststelling en publicatie van de jaarrekening en aansprakelijkheid in het kader daarvan. Een reactie $\cdot$ Maandblad voor Ondernemingsre...

Kort en goed, zolang de wetgever artikel 2:210 lid 5 BW niet geschrapt of gewijzigd heeft of indien niet statutair van deze bepaling is afgeweken, zijn oplettendheid en tijdig deponeren vereist om te voorkomen dat het onweerlegbare vermoeden van onbehoorlijk bestuur zal gelden en de bestuurder daardoor in een lastige(re) procespositie komt te verkeren. Better safe than sorry. En een adviseur moet de bestuurder in ieder geval wijzen op de risico's die het overschrijden van deze termijn met zich brengen, zodat de bestuurder een weloverwogen beslissing kan nemen. ${ }^{29}$ Meer en anders hebben wij in onze eerdere bijdrage in het Tijdschrift voor vennootschapsrecht, rechtspersonenrecht en ondernemingsbestuur niet gesteld. ${ }^{30}$

\section{Noten}

1 J.E.P.A. van Hooff, Aansprakelijkheid voor het boedeltekort en de publicatieplicht: wat is te laat deponeren?, MvO 2015, afl. 1/2, p. 29-34.

2 Zie de door Van Hooff 2015 aangehaalde literatuur.

3 Kamerstukken 33771, Stb. 2014, 540 (publicatie wet) en 541 (gedeeltelijke inwerkingtreding) en Stb. 2015, 247 (gedeeltelijke inwerkingtreding).

4 Kamerstukken 34176, Stb. 2015, 349 (publicatie wet) en 351 (inwerkingtreding per 1 november 2015).

5 Art. 2:210 lid 1 en 2 BW.

6 Art. 2:210 lid 3 t/m 7 BW.

7 Art. 2:394 lid 1 t/m 3 BW.

8 Van Hooff 2015, p. 32.

9 HR 11 juni 1993, NJ 1993/713 m.nt. Ma (Brens q.q./Sarper).

10 Zie ook Van der Heijden \& Van der Grinten/Dortmond, Handboek voor de Naamloze en de Besloten Vennootschap, Deventer: Kluwer 2013, nr. 330.1, p. 723.

11 Van Hooff 2015, p. 33, r.k.

12 Kamerstukken II 2014/15, 34176, 3, p. 34 (MvT).

13 Daarbij wordt ervan uitgegaan dat de vaststelling binnen de uiterste publicatietermijn van dertien maanden van art. 2:394 lid 3 BW plaatsvindt.

14 Kamerstukken II 2013/14, 33771, 3, p. 6 (MvT).

15 Wijziging van de Handelsregisterwet 2007, het Burgerlijk Wetboek en de Wet op de formeel 
17-2-2016 Perikelen rond de vaststelling en publicatie van de jaarrekening en aansprakelijkheid in het kader daarvan. Een reactie $\cdot$ Maandblad voor Ondernemingsre...

buitenlandse vennootschappen in verband met deponering van bescheiden in het handelsregister langs elektronische weg, Kamerstukken 34262, Stb. 2015, 505.

16 Op 8 december 2015 heeft de Eerste Kamer het wetsvoorstel als hamerstuk afgedaan.

17 HR 20 oktober 2006, ECLI:NL:HR:2006:AY7916, NJ 2007/2 m.nt. Ma, r.o. 4.4.1.

18 Van Hooff 2015, p. 32. In zijn conclusie in par. 3 op p. 34 formuleert Van Hooff het zuiverder.

19 HR 30 november 2007, NJ 2008/91 m.nt. Ma (Blue Tomato). Zie ook Asser/Maeijer \& Kroeze 2-I* 2015/570 onder c.

20 C.A. Schwarz \& R.A. Wolf, De vereenvoudigde vastgestelde jaarrekening. De gemiste kans van (het voorstel van) de Verzamelwet Veiligheid en Justitie 2013, TvOB 2014, afl. 1, p. 27-28.

21 HR 11 juni 1993, NJ 1993/713 m.nt. Ma (Brens q.q./Sarper).

22 Asser/Maeijer \& Kroeze 2-I* 2015/569; H. Beckman, Depot van de jaarrekening en andere daarmee verband houdende jaarrekeningperikelen, Ondernemingsrecht 2013/59; H. Beckman, Hoofdlijnen van het jaarrekeningenrecht in Nederland, Deventer: Kluwer 2013, p. 684; H. Beckman e.a., Sdu Commentaar Ondernemingsrecht, Den Haag: Sdu Uitgevers 2015, art. 2:394 BW, aant. C1, laatste alinea (bijgewerkt tot 2 april 2015).

23 Van Hooff 2015, p. 30-33 en de aldaar in de noten genoemde literatuur.

24 Kamerstukken II 1987/88, 20556, 3, p. 5 (MvT).

25 Schwarz \& Wolf 2014, p. 27-28.

26 Kamerstukken II 1983/84, 16631, 6, p. 18, 22 en 27 (MvA).

27 Kamerstukken II 2013/14, 33771, 3, p. 6 (MvT).

28 HR 1 november 2013, ECLI:NL:HR:2013:1079, NJ 2014/7 m.nt. P. van Schilfgaarde (Verify), r.o. 3.6.2 en 3.6.4. Zie ook HR 12 juli 2013, ECLI:NL:HR:2013:BZ7189, NJ 2013/401 (Apeldoornse Asbestsanering).

29 Vgl. HR 29 mei 2015, ECLI:NL:HR:2015:1406, NJ 2015/267.

30 Schwarz \& Wolf 2014 